\title{
Blood pressure elevation in hemodialysis patients after the Great East Japan Earthquake
}

\author{
Yoshihiro Tani ${ }^{1}$, Masaaki Nakayama ${ }^{1}$, Kenichi Tanaka ${ }^{1}$, Yoshimitsu Hayashi ${ }^{1}$, Koichi Asahi ${ }^{1}$, \\ Tatsuhiko Kamata ${ }^{2}$, Masahiko Ogihara ${ }^{3}$, Keiji Sato ${ }^{4}$, Masato Matsushima ${ }^{5}$ and Tsuyoshi Watanabe ${ }^{1}$
}

A major earthquake measuring 9.0 on the Richter scale struck northeastern Japan at 2:46 pm on 11 March 2011 . Several reports have described transient increases in blood pressure after major earthquakes, but the impact of such increases on hemodialysis patients has not been reported. We retrospectively investigated changes in blood pressure and influencing factors in 205 patients (mean age 66.6 \pm 13.0 years; male 51.7\%; median dialysis vintage $6.0(2.0-11.0)$ years) on chronic dialysis at three dialysis centers in the affected area (Fukushima City) for 8 weeks after the earthquake. Pre-dialysis blood pressure was significantly elevated at 1 week after the earthquake compared with baseline (systolic vs. diastolic blood pressure: 153.1 $\pm 20.2 /$ $80.1 \pm 13.5$ vs. $148.6 \pm 20.0 / 77.5 \pm 12.8 \mathrm{~mm} \mathrm{Hg}, P<0.001$ ), similarly post-dialysis blood pressure was elevated for up to 8 weeks. Independent factors influencing changes in blood pressure after the earthquake comprised baseline blood pressure and $\alpha$-blockers. The earthquake induced a significant elevation in blood pressure among patients on chronic dialysis, and activation of the sympathetic nervous system might at least in part be associated with the mechanism underlying this increase. Hypertension Research (2014) 37, 139-144; doi:10.1038/hr.2013.116; published online 3 October 2013

Keywords: blood pressure; dialysis; earthquake; hypertension; sympatholytics

\section{INTRODUCTION}

Acute and chronic psychological stress caused by natural disasters is closely associated with a subsequent increase in cardiovascular accidents and mortality. ${ }^{1,2}$ Stress induced by major disasters is thought to activate the sympathetic nervous system. ${ }^{3,4}$ These responses result in the development of metabolic and hemodynamic alterations such as hyperlipidemia, hyperglycemia, endothelial dysfunction, increased blood viscosity and increased blood pressure, which are collectively referred to as disaster hypertension. ${ }^{5}$

The development of hypertension after disasters was initially described in a 1948 study conducted after a fertilizer explosion in Texas City, Texas, USA on 16 April 1947 killed over 500 people and injured thousands. ${ }^{6}$ Since then, accumulating data have revealed a causal relationship between major earthquakes and elevated blood pressure in hypertensive patients. ${ }^{7-21}$ Such data include the 1980 Southern Italy earthquake (magnitude 6.7 on the Richter scale), ${ }^{7-9}$ the 1995 Hanshin-Awaji earthquake in Japan (magnitude 7.2 on the Richter scale), ${ }^{10-15}$ the 1998 central Italy earthquake (magnitude 4.7 on the Richter scale), ${ }^{16}$ the 2004 Mid-Niigata earthquake (magnitude 6.8 on the Richter scale), ${ }^{17,18}$ the 2008 Wenchuan earthquake in China (magnitude 8.0 on the Richter scale) ${ }^{19}$ and the 2011 Great East Japan Earthquake (magnitude 9.0 on the Richter scale). ${ }^{21-23}$

Changes in blood pressure were discovered during clinic visits, ${ }^{7-9,11,13,15,18,22}$ while measuring home blood pressure ${ }^{12,17,21,23}$ and during ambulatory blood pressure monitoring, ${ }^{10,14,16,19,20}$ and the values returned to baseline within 6 weeks. ${ }^{11-13,15}$ Exaggerated and prolonged activation of the sympathetic nervous system by earthquake stress is supposed to be involved with this pathological mechanism, ${ }^{3,4}$ and it could increase the risk for cardiovascular disease (CVD) among the inhabitants of affected areas. ${ }^{24,25}$

Patients with chronic kidney disease, particularly those on maintenance dialysis therapy, are at high risk for CVD-related morbidity and mortality, ${ }^{26-32}$ owing to various underlying factors such as fluid accumulation, sympathetic nervous activation, arteriosclerosis and endothelial dysfunction. ${ }^{33}$

Accordingly, the impact of natural disasters upon patients undergoing dialysis might have significant relevance, but no data have been published in this regard. Here, we examined the impact of the Great East Japan Earthquake on the blood pressure of patients undergoing regular hemodialysis therapy in the devastated area.

\section{METHODS}

Study district and population

The Great East Japan Earthquake (magnitude 9.0 on the Richter scale) was followed by a tsunami that struck the coast of northeastern Japan on 11 March 2011. The death toll was 15841, with 3485 missing. Fukushima City (population, 294000), located $180 \mathrm{~km}$ from the epicenter, is an area that was affected by the earthquake. Although the residents in the city faced transient

\footnotetext{
${ }^{1}$ Department of Nephrology and Hypertension, Fukushima Medical University School of Medicine, Fukushima, Japan; ${ }^{2}$ Division of Urology, Fukushima Minami Junkankika Hospital, Fukushima, Japan; ${ }^{3}$ Ogihara Clinic, Fukushima, Japan; ${ }^{4}$ Division of Nephrology, Fujita General Hospital, Fukushima, Japan and ${ }^{5}$ Division of Clinical Epidemiology, Jikei University School of Medicine, Tokyo, Japan

Correspondence: Dr Y Tani, Department of Nephrology and Hypertension, Fukushima Medical University School of Medicine, Hikarigaoka 1, Fukushima 960-1295, Japan. E-mail: taniyo@fmu.ac.jp

Received 13 September 2012; revised 21 May 2013; accepted 6 July 2013; published online 3 October 2013
} 
damage to lifelines such as limited water and gasoline supplies during the first week after the earthquake, the destruction of homes and buildings was limited, and the city was not affected by the subsequent tsunami that hit the coast. Approximately 900 patients were on regular dialysis in Fukushima City before the earthquake (information obtained from The Japanese Society for Dialysis Therapy survey conducted at the end of 2010).

We retrospectively analyzed blood pressure in 205 individuals who had been undergoing regular hemodialysis at three dialysis centers in Fukushima City (Fukushima Minami Junkankika (FM) Hospital, Ogihara (O) Clinic and Fujita General (FG) Hospital) between 28 February and 7 May 2011. Table 1 shows the profiles of the patients. We excluded patients who fled the coastal area that was seriously damaged by the tsunami after the earthquake, those with immediate relatives who died or were injured, those whose homes were destroyed and those who were physically injured.

We defined the period from 28 February - 5 March as baseline (1 week before the earthquake) and the periods from 14 to 19 March, 21 to 26 March, 4 to 9 April, 18 to 23 April and 18 to 23 May as 1, 2, 4, 6 and 8 weeks, respectively, after the earthquake. Importantly, no significant changes were

Table 1 Profiles of the patients

\begin{tabular}{|c|c|}
\hline & $N=205$ \\
\hline Age (years) & $66.6 \pm 13.0$ \\
\hline Male, n (\%) & $106(51.7)$ \\
\hline Dialysis vintage (years) & $6.0(2.0-11.0)$ \\
\hline \multicolumn{2}{|l|}{ Pre dialysis } \\
\hline Systolic blood pressure (mm Hg) & $148.1 \pm 19.5$ \\
\hline Diastolic blood pressure $(\mathrm{mm} \mathrm{Hg})$ & $77.3 \pm 12.8$ \\
\hline Pulse rate (per min) & $77.0 \pm 11.9$ \\
\hline \multicolumn{2}{|l|}{ Post dialysis } \\
\hline Systolic blood pressure (mm Hg) & $141.7 \pm 20.8$ \\
\hline Diastolic blood pressure $(\mathrm{mm} \mathrm{Hg})$ & $75.2 \pm 12.5$ \\
\hline Pulse rate (per min) & $72.8 \pm 12.0$ \\
\hline Body weight (kg) & $54.5 \pm 11.6$ \\
\hline \multicolumn{2}{|l|}{ Underlying kidney disease, $n$ (\%) } \\
\hline Diabetic nephropathy & $79(38.5)$ \\
\hline Nephrosclerosis & 49 (23.9) \\
\hline Chronic glomerulonephritis & $42(20.5)$ \\
\hline Others & $35(17.0)$ \\
\hline \multicolumn{2}{|l|}{ Comorbidity, n (\%) } \\
\hline Hypertension & $187(91.2)$ \\
\hline Diabetes & $87(42.4)$ \\
\hline Hyperlipidemia & $54(26.3)$ \\
\hline \multicolumn{2}{|l|}{ Medical history, n (\%) } \\
\hline Cardiovascular disease & $69(33.7)$ \\
\hline \multicolumn{2}{|l|}{ Anti-hypertensive agents, $n$ (\%) } \\
\hline RAS-I & $144(70.2)$ \\
\hline CCB & $124(60.5)$ \\
\hline$\alpha$-Blockers & $42(20.5)$ \\
\hline$\beta$-Blockers & $38(18.5)$ \\
\hline Diuretics & $59(28.8)$ \\
\hline DRI & $24(11.7)$ \\
\hline
\end{tabular}

Abbreviations: ACE-I, angiotensin-converting enzyme inhibitor; ARB, angiotensin-receptor blocker; CCB, calcium channel blocker; DRI, direct renin inhibitor; RAS-I, renin-angiotensin system inhibitor.

Numerical data are presented as means \pm s.d. for normal distribution, and otherwise as medians and interquartile ranges (dialysis vintage). Categorical variables are expressed as ratios (\%). found in pre- and post-dialysis mean blood pressure values among 207 patients who had been treated at the three dialysis centers during the same period of the previous year (between 1 March and 4 May 2010).

We analyzed the time course of changes in blood pressure among the patients and possible influences on changes in the blood pressure after the earthquake.

The Ethics Committees of Fukushima Medical University School of Medicine approved the study protocol, which complied with the tenets of the Declaration of Helsinki. The procedures and possible risks of the study were explained to all of the patients, who then provided written informed consent to participate.

\section{Data collection}

Systolic and diastolic blood pressure as well as pulse rates were measured in supine participants using oscillometric devices provided with the dialysis machines. Pre-dialysis blood pressure and pulse rates were measured after $5 \mathrm{~min}$ of rest and before the dialysis needle was inserted. Post-dialysis blood pressure and pulse rates were recorded at $5 \mathrm{~min}$ after completing each hemodialysis session. Values for blood pressure, pulse rate and body weight at each time point were averaged for the analysis.

Clinical data were obtained from a review of the medical records of the participants. We defined CVD as a history of myocardial infarction, coronary artery bypass or angioplasty, carotid endarterectomy, stroke, peripheral bypass, peripheral angioplasty or amputation. Diabetes was defined as plasma glucose $>200 \mathrm{mg} \mathrm{dl}^{-1}$ at any time, fasting glucose $>126 \mathrm{mg} \mathrm{dl}^{-1}$ or the use of insulin or oral hypoglycemic drugs. Hyperlipidemia was defined as medication with lipid-lowering drugs or low-density lipoprotein cholesterol $>140 \mathrm{mg} \mathrm{dl}^{-1}$, triglycerides $>150 \mathrm{mg} \mathrm{dl}^{-1}$ and high-density lipoprotein cholesterol $<40 \mathrm{mg} \mathrm{dl}^{-1}$ in men and $<50 \mathrm{mg} \mathrm{dl}^{-1}$ in women. A single sample was taken from dry dialysis needles before the dialysis sessions started.

\section{Statistical analysis}

Continuous variables are expressed as the mean \pm s.d. for those with a normal distribution and otherwise as median values and interquartile ranges. We determined whether continuous variables such as blood pressure significantly differed after the earthquake using a paired $t$-test or the Wilcoxon signed-rank test with the Bonferroni correction. For example, when five tests were predefined and conducted per variable (baseline vs. 1, 2, 4, 6 and 8 weeks), $0.05 / 5(=0.01)$ was considered significant to adjust for the $\alpha$-level. We used multiple regression analyses to assess anti-hypertensive agents such as reninangiotensin system inhibitors, calcium channel blockers, $\alpha$-blockers, $\beta$-blockers, diuretics and direct renin inhibitors, which could contribute to changes in blood pressure after disasters. Dichotomous variables were entered into regression models as indicator variables (yes $=1 ;$ no $=0$ ).

\section{RESULTS}

Among the 205 patients, 196 were on dialysis on 7 May 2011. Two patients died, and seven fled or underwent dialysis at other centers after the earthquake. The mean durations of dialysis were $4.3 \pm 0.6$, $3.9 \pm 0.3$, and $3.8 \pm 0.3 \mathrm{~h}$ at $\mathrm{O}$ clinic and at the FG and FM hospitals, respectively, before the earthquake, and the duration was reduced to $3 \mathrm{~h}$ at all three dialysis centers during the 2 weeks after the earthquake.

Changes in blood pressure during the $\mathbf{8}$ weeks after the earthquake Pre-dialysis systolic and diastolic blood pressures were significantly elevated at 1 week after the earthquake compared with baseline $(P<0.01)$ (Table 2). However, these values returned to baseline at 2 weeks after the earthquake. Post-dialysis systolic blood pressure was significantly elevated at 1,2, 4, 6 and 8 weeks after the earthquake compared with baseline $(P<0.01)$, and post-dialysis diastolic blood pressure remained significantly elevated at 1,2 and 6 weeks after the earthquake compared with baseline $(P<0.01)$. 
Table 2 Changes in pre- and post-dialysis systolic and diastolic blood pressure, body weight, pulse rate and laboratory parameters between baseline values and 1-8 weeks after the earthquake

\begin{tabular}{|c|c|c|c|c|c|c|}
\hline & Baseline & 1 Week & 2 Weeks & 4 Weeks & 6 Weeks & 8 Weeks \\
\hline \multicolumn{7}{|l|}{ Pre dialysis } \\
\hline Systolic blood pressure (mm Hg) & $148.6 \pm 20.0$ & $153.1 \pm 20.2^{a}$ & $150.7 \pm 19.8$ & $147.1 \pm 19.2$ & $150.9 \pm 20.0$ & $149.6 \pm 19.0$ \\
\hline Diastolic blood pressure (mm Hg) & $77.5 \pm 12.8$ & $80.1 \pm 13.5^{\mathrm{a}}$ & $78.6 \pm 12.0$ & $77.0 \pm 12.2$ & $78.0 \pm 12.3$ & $77.1 \pm 11.7$ \\
\hline Body weight $(\mathrm{kg})$ & $55.4(47.7-64.7)$ & $55.3(47.5-64.3)^{a}$ & $55.2(47.8-64.2)^{\mathrm{a}}$ & $55.5(47.7-64.6)$ & $55.5(47.7-64.6)$ & $55.4(47.8-64.6)$ \\
\hline Pulse rate (per min) & $75.6(69.3-84.6)$ & $76.3(70.3-87.3)^{a}$ & $75.6(67.0-83.3)^{a}$ & $74.0(66.6-84.6)$ & $76.0(67.6-84.6)$ & $75.0(67.6-84.6)$ \\
\hline \multicolumn{7}{|l|}{ Post dialysis } \\
\hline Systolic blood pressure (mm Hg) & $141.9 \pm 20.7$ & $148.5 \pm 21.7^{a}$ & $149.8 \pm 20.6^{a}$ & $146.4 \pm 20.9^{a}$ & $148.7 \pm 22.1^{\mathrm{a}}$ & $146.9 \pm 21.7^{a}$ \\
\hline Diastolic blood pressure (mm Hg) & $75.2 \pm 12.2$ & $77.7 \pm 12.9^{a}$ & $78.0 \pm 12.1^{\mathrm{a}}$ & $76.4 \pm 12.8$ & $77.3 \pm 13.3^{a}$ & $76.4 \pm 12.0$ \\
\hline Body weight $(\mathrm{kg})$ & $53.1(45.4-62.5)$ & $53.3(45.9-62.5)$ & $53.4(45.7-62.4)$ & $53.3(45.6-62.6)$ & $53.2(45.6-62.3)^{a}$ & $53.6(45.6-62.3)^{a}$ \\
\hline Pulse rate (per min) & $72.3(62.6-79.3)$ & $72.0(64.0-80.0)$ & $71.3(62.3-79.6)$ & $71.3(64.0-80.6)$ & $70.6(62.6-78.0)^{a}$ & $69.6(61.6-79.0)^{a}$ \\
\hline \multicolumn{7}{|l|}{ Laboratory parameters } \\
\hline Total protein $\left(\mathrm{gdl}^{-1}\right.$ ) & $6.4(6.2-6.8)$ & - & $6.4(6.1-6.8)$ & - & $6.5(6.2-6.9)$ & - \\
\hline Hemoglobin $\left(\mathrm{g} \mathrm{dl}^{-1}\right)$ & $10.0(9.4-10.7)$ & - & $9.8(9.1-10.5)^{a}$ & - & $9.8(9.1-10.4)^{a}$ & - \\
\hline Urea $\left(\mathrm{mg} \mathrm{dl}^{-1}\right)$ & $55.9 \pm 14.0$ & - & $54.6 \pm 14.0$ & - & $57.0 \pm 14.4$ & - \\
\hline Creatinine $\left(\mathrm{mg} \mathrm{dl}^{-1}\right)$ & $9.8(7.9-11.3)$ & - & $9.9(8.0-11.5)^{\mathrm{b}}$ & - & $9.8(8.1-11.3)$ & - \\
\hline Uric acid (mg dl-1) & $6.7 \pm 1.4$ & - & $6.6 \pm 1.3$ & - & $6.9 \pm 1.4^{\mathrm{b}}$ & - \\
\hline Sodium $\left(m E q I^{-1}\right)$ & $140(138-142)$ & - & $141(139-143)^{a}$ & - & $140(139-142)$ & - \\
\hline Potassium ( $\mathrm{mEq} \mathrm{I}{ }^{-1}$ ) & $4.7 \pm 0.6$ & - & $4.8 \pm 0.7$ & - & $4.8 \pm 0.7$ & - \\
\hline Chloride $\left(\mathrm{mEql} \mathrm{I}^{-1}\right)$ & 105 (103-108) & - & $105(104-108)^{\mathrm{b}}$ & - & 105 (103-105) & - \\
\hline Calcium (mg dl ${ }^{-1}$ ) & $8.8(8.4-9.2)$ & - & $8.7(8.3-9.1)^{\mathrm{a}}$ & - & $8.7(8.4-9.1)^{a}$ & - \\
\hline Phosphorus (mg dl ${ }^{-1}$ ) & $4.6(3.9-5.3)$ & - & $4.5(3.8-5.1)$ & - & $4.8(4.1-5.5)$ & - \\
\hline
\end{tabular}

Data are shown as means \pm s.d. for normal distribution and otherwise as medians and interquartile ranges. Differences between periods were evaluated using paired $t$-tests or the Wilcoxon signed rank test with the Bonferroni multiple comparison correction. ${ }^{\mathrm{a}} P<0.01$ and ${ }^{\mathrm{b}} P=0.01$ vs. baseline.

\section{Factors influencing changes in blood pressure}

We analyzed possible factors influencing the significant change in blood pressure during the first week after the earthquake (Table 3). Multivariate regression analysis was used to compare pre- (or post-) dialysis systolic (or diastolic) blood pressure at 1 week after the earthquake with baseline as a dependent variable. The adjusted potential confounding variables in these regression models were age, gender, dialysis vintage, hypertension, diabetes, hyperlipidemia, CVD, pre- (or post-) dialysis systolic (or diastolic) blood pressure at baseline, pre- (or post-) dialysis heart rate at baseline and antihypertensive agents.

Pre-dialysis systolic blood pressure at baseline was identified as an independent factor influencing a change in the pre-dialysis systolic blood pressure at 1 week after the earthquake $(\beta-0.29, P<0.01)$. Baseline post-dialysis systolic (or diastolic) blood pressure was also independently related to changes in post-dialysis systolic (or diastolic) blood pressure at 1 week after the earthquake (systolic, $\beta-0.30$, $P<0.01$; diastolic, $\beta-0.19, P<0.01$ ).

Among the anti-hypertensive agents, $\alpha$-blockers were identified as independent suppressive factors of a change in pre-dialysis systolic blood pressure at 1 week after the earthquake $(\beta-0.15$, $P=0.03)$. Furthermore, multivariate analysis revealed that $\alpha$-blockers remained an independent factor for changes in systolic and diastolic blood pressure for several weeks after the earthquake (Supplementary Data).

Moreover, renin-angiotensin system inhibitors were also identified as an independent suppressive factor for a change in pre-dialysis diastolic blood pressure but only at 1 week after the earthquake $(\beta-0.15, P=0.03) \quad$ (Supplementary Data). Figure 1 shows the changes in blood pressure over a period of 8 weeks in patients with or without $\alpha$-blockers.

\section{DISCUSSION}

This study is the first to show the time course of changes in blood pressure among patients on regular dialysis after a major earthquake. Blood pressure became significantly elevated in hemodialysis patients after the Great East Japan Earthquake. Moreover, blood pressure at baseline and treatment with $\alpha$-blockers were significantly associated with changes in blood pressure.

Blood pressure in patients with low blood pressure at baseline significantly changed after the earthquake. Accordingly, the results might suggest that patients with relatively low blood pressure at baseline tended to be more affected by the earthquake, possibly due to exaggerated sympathetic activation. Whether such patients could be at high risk of CVD development after earthquakes might be clinically significant and should be assessed in the future.

Stress activates the sympathetic nervous system ${ }^{3,4}$ and influences the aggravation of blood pressure. ${ }^{34-37}$ We found that blood pressure was less aggravated in patients treated with $\alpha$-blockers (Figure 1), which comprised an independent suppressive factor for changes in blood pressure during the study period even after adjusting for confounders. These findings indicated that sympathetic activation has a central role in the mechanism of blood pressure elevation after earthquakes. In addition, renin-angiotensin system inhibitors were also an independent suppressive factor for changes in pre-dialysis diastolic blood pressure but only during the first week after the earthquake. We speculate that a reduced circulating blood volume transiently activated the renin-angiotensin system during this time. This hypothesis needs to be tested in the future.

This study has some limitations. First, the post-observational protocol cannot completely exclude all factors that might influence the control of blood pressure, such as temperature, salt intake and individual variations in the ability to cope with external stress. 
Table 3 Factors contributing to changes in blood pressure at 1 week after the earthquake

(A) Pre dialysis

\begin{tabular}{|c|c|c|c|c|c|c|c|c|}
\hline & \multicolumn{2}{|c|}{ Univariate } & \multicolumn{2}{|c|}{$\begin{array}{c}\text { Multivariate } \\
\mathrm{R}^{2}=0.09\end{array}$} & \multicolumn{2}{|c|}{ Univariate } & \multicolumn{2}{|c|}{$\begin{array}{l}\text { Multivariate } \\
\mathrm{R}^{2}=0.02\end{array}$} \\
\hline & $r$ & P-value & B & P-value & $r$ & P-value & B & P-value \\
\hline Dialysis vintage (years) & -0.03 & 0.32 & & NS & -0.07 & 0.15 & & NS \\
\hline Hypertension & -0.11 & 0.05 & & NS & -0.12 & 0.33 & & NS \\
\hline Diabetes & -0.05 & 0.23 & & NS & -0.01 & 0.42 & & NS \\
\hline Hyperlipidemia & 0.03 & 0.31 & & NS & 0.05 & 0.22 & & NS \\
\hline Cardiovascular disease & 0.07 & 0.15 & & NS & 0.07 & 0.13 & & NS \\
\hline Pre-dialysis systolic/diastolic blood pressure at baseline $(\mathrm{mm} \mathrm{Hg})$ & -0.33 & $<0.01$ & -0.29 & $<0.01$ & -2.00 & $<0.01$ & & NS \\
\hline$\beta$-Blockers & -0.09 & 0.08 & & NS & -0.09 & 0.09 & & NS \\
\hline Diuretics & -0.09 & 0.09 & & NS & -0.01 & 0.41 & & NS \\
\hline DRI & -0.08 & 0.11 & & NS & -0.12 & 0.03 & & NS \\
\hline
\end{tabular}

(B) Post dialysis

\begin{tabular}{|c|c|c|c|c|c|c|c|c|}
\hline & \multicolumn{4}{|c|}{ Change in systolic blood pressure } & \multicolumn{4}{|c|}{ Change in diastolic blood pressure } \\
\hline & \multirow{2}{*}{\multicolumn{2}{|c|}{ Univariate }} & \multirow{2}{*}{\multicolumn{2}{|c|}{$\begin{array}{c}\text { Multivariate } \\
\mathrm{R}^{2}=0.10\end{array}$}} & \multirow{2}{*}{\multicolumn{2}{|c|}{ Univariate }} & \multirow{2}{*}{\multicolumn{2}{|c|}{$\begin{array}{c}\text { Multivariate } \\
\mathrm{R}^{2}=0.03\end{array}$}} \\
\hline & & & & & & & & \\
\hline & $\mathrm{R}$ & P-value & B & P-value & $\mathrm{r}$ & P-value & B & P-value \\
\hline Age (years) & -0.01 & 0.39 & & NS & -0.01 & 0.40 & & NS \\
\hline Gender (male) & -0.01 & 0.43 & & NS & -0.05 & 0.22 & & NS \\
\hline Dialysis vintage (years) & -0.005 & 0.47 & & NS & 0.02 & 0.38 & & NS \\
\hline Hypertension & 0.003 & 0.48 & & NS & -0.005 & 0.47 & & NS \\
\hline Diabetes & -0.04 & 0.28 & & NS & 0.002 & 0.48 & & NS \\
\hline Hyperlipidemia & 0.001 & 0.49 & & NS & 0.03 & 0.29 & & NS \\
\hline Cardiovascular disease & 0.04 & 0.25 & & NS & 0.02 & 0.35 & & NS \\
\hline Post-dialysis systolic/ diastolic blood pressure at baseline $(\mathrm{mm} \mathrm{Hg})$ & -0.25 & $<0.01$ & -0.30 & $<0.01$ & -0.18 & $<0.01$ & -0.19 & $<0.01$ \\
\hline Post-dialysis heart rate at baseline (per min) & 0.06 & 0.38 & & NS & 0.02 & 0.38 & & NS \\
\hline RAS-I & 0.03 & 0.33 & & NS & -0.01 & 0.43 & & NS \\
\hline $\mathrm{CCB}$ & 0.11 & 0.05 & 0.18 & 0.01 & 0.05 & 0.20 & & NS \\
\hline$\alpha$-Blockers & -0.03 & 0.29 & & NS & -0.11 & 0.05 & & NS \\
\hline$\beta$-Blockers & 0.01 & 0.39 & & NS & -0.10 & 0.06 & & NS \\
\hline Diuretics & -0.06 & 0.18 & & NS & -0.06 & 0.17 & & NS \\
\hline DRI & -0.02 & 0.37 & & NS & -0.02 & 0.35 & & NS \\
\hline
\end{tabular}

Abbreviations: CCB calcium channel blocker; CVD, cardiovascular disease; DRI, direct renin inhibitor; RAS-I, renin-angiotensin inhibitor.

Multivariate logistic regression analysis included pre-dialysis changes in systolic (or diastolic) blood pressure at 1 week (A) and post-dialysis changes in systolic (or diastolic) blood pressure at

1 week (B) as dependent variables. Adjusted potential confounding variables comprised age, gender, dialysis vintage, hypertension, diabetes, hyperlipidemia, CVD, pre- (or post-) dialysis systolic

(or diastolic) blood pressure at baseline, pre- (or post-) dialysis heart rate at baseline, RAS-I, CCB, $\alpha$-blockers, $\beta$-blockers, diuretics and DRI.

Furthermore, we cannot provide control blood pressure values derived from patients in Japan who had never been affected by the earthquake because it was closely followed by the Fukushima-Daiichi nuclear power plant disaster, which resulted in nationwide social panic. However, blood pressure in patients on dialysis did not significantly change at the three centers during the same period of the year before the earthquake (2010). Therefore, disaster-related factors most likely increased blood pressure in these patients. Second, although several reports have documented increased heart rates after earthquakes, ${ }^{7,8,16}$ the changes in heart rate were not significant in the present study. We suppose that these contradictory findings may have been influenced by the timing of data sampling and the medical 

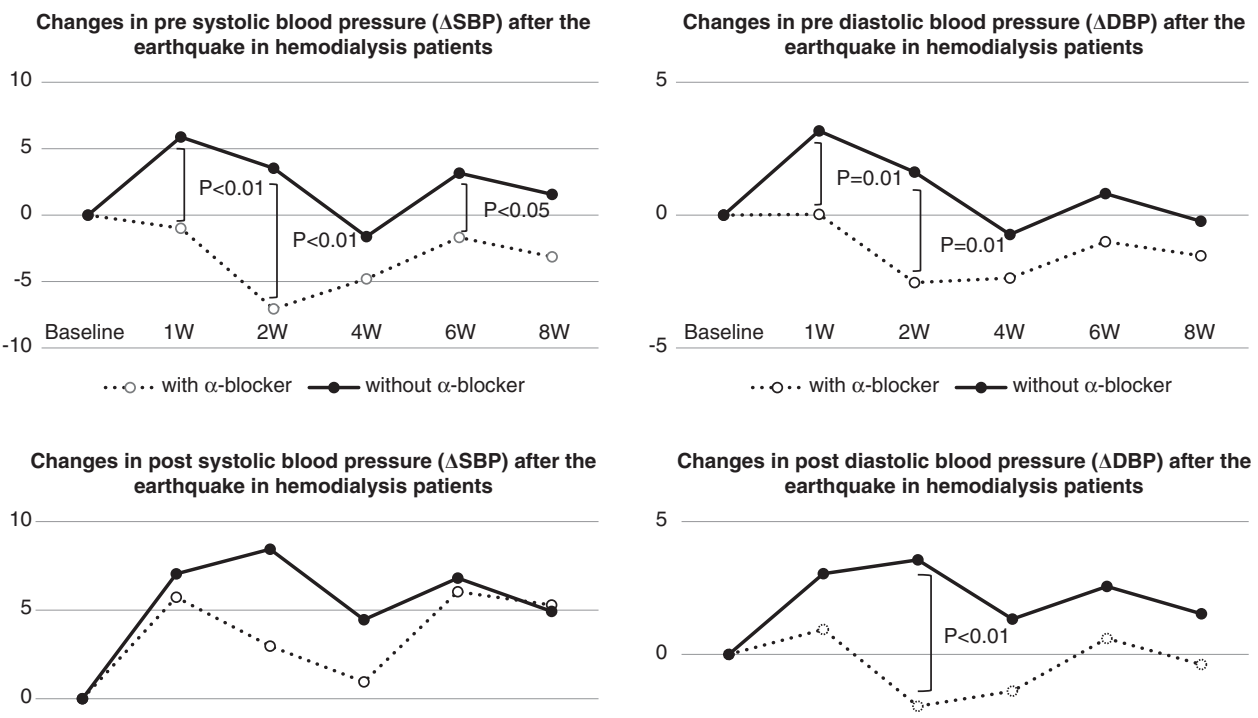

$-5 \frac{\text { Baseline } 1 \mathrm{~W} \quad 2 \mathrm{~W} \quad 4 \mathrm{~W} \quad 6 \mathrm{~W} \quad 8 \mathrm{~W}}{\ldots \text { o. . with } \alpha \text {-blocker } \rightarrow \text { without } \alpha \text {-blocker }}$

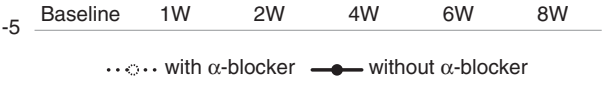

Figure 1 Changes in pre- and post-systolic and diastolic blood pressure in groups medicated with or without $\alpha$-blockers for 8 weeks after the earthquake. With $(\bigcirc)$ vs. without $(\bigcirc) \alpha$-blockers (unpaired $t$-test).

backgrounds of the patients. The present study analyzed data from maintenance hemodialysis patients several days after the disaster, and this patient group is frequently associated with autonomic dysfunction. Third, we could not exclude the possibility that excess body fluid accumulation was associated with the mechanism of elevated blood pressure among dialysis patients because brain natriuretic peptide and human atrial natriuretic peptide data were unavailable. Finally, $80 \%$ of the patients in the present study were prescribed with calcium channel blockers and/or renin-angiotensin system inhibitors, and none were prescribed only $\alpha$-blockers. Although we identified $\alpha$-blockers as a significant factor for ameliorating earthquake hypertension, the clinical significance of this agent remains to be determined.

In conclusion, the present study demonstrated that the Great East Japan Earthquake significantly increased blood pressure in patients on dialysis and that an activated sympathetic nervous system could be involved, at least in part, in the mechanism.

\section{CONFLICT OF INTEREST}

The authors declare no conflict of interest.

\section{ACKNOWLEDGEMENTS}

These results were presented as a poster at the American Society of Nephrology, Philadelphia, Pennsylvania, 2011. This study was partially supported by Banyu Life Science Foundation International.

1 Leor J, Poole WK, Kloner RA. Sudden cardiac death triggered by an earthquake. N Engl J Med 1996; 334: 413-419.

2 Dobson AJ, Alexander HM, Malcolm JA, Steele PL, Miles TA. Heart attacks and the Newcastle earthquake. Med J Aust 1991; 155: 757-761.

3 McEwen BS. Stress, adaptation, and disease. Allostasis and allostatic load. Ann NY Acad Sci 1998; 840: 33-44.

4 McEwen BS. Central effects of stress hormones in health and disease: Understanding the protective and damaging effects of stress and stress mediators. Eur J Pharmacol 2008; 583: 174-185.
5 Kario K, McEwen BS, Pickering TG. Disasters and the heart: a review of the effects of earthquake-induced stress on cardiovascular disease. Hypertens Res 2003; 26 : 355-367.

6 Ruskin A, Beard OW, Schaffer RL. Blast hypertension; elevated arterial pressures in the victims of the Texas City disaster. Am J Med 1948; 4: 228-236.

7 Trevisan M, Celentano E, Meucci C, Farinaro E, Jossa F, Krogh V, Giumetti D, Panico S, Scottoni A, Mancini M. Short-term effect of natural disasters on coronary heart disease risk factors. Arteriosclerosis 1986; 6: 491-494.

8 Trevisan M, Jossa F, Farinaro E, Krogh V, Panico S, Giumetti D, Mancini M. Earthquake and coronary heart disease risk factors: a longitudinal study. Am J Epidemiol 1992; 135: 632-637.

9 Bland SH, Farinaro E, Krogh V, Jossa F, Scottoni A, Trevisan M. Long-term relations between earthquake experiences and coronary heart disease risk factors. Am J Epidemiol 2000; 151: 1086-1090.

10 Kario K, Matsuo T, Shimada K. Follow-up of white-coat hypertension in the HanshinAwaji earthquake. Lancet 1996; 347: 626-627.

11 Kario K, Matsuo T, Kobayashi H, Yamamoto K, Shimada K. Earthquake-induced potentiation of acute risk factors in hypertensive elderly patients: possible triggering of cardiovascular events after a major earthquake. J Am Coll Cardiol 1997; 29: 926-933.

12 Minami J, Kawano Y, Ishimitsu T, Yoshimi H, Takishita S. Effect of the Hanshin-Awaji earthquake on home blood pressure in patients with essential hypertension. Am J Hypertens 1997; 10: 222-225.

13 Saito K, Kim JI, Maekawa K, Ikeda Y, Yokoyama M. The great Hanshin-Awaji earthquake aggravates blood pressure control in treated hypertensive patients. Am J Hypertens 1997; 10: 217-221.

14 Kario K, Suzuki T, Nakagawa Y, Mitsuhashi T, Shimada K. White-coat hypertension triggered by iatrogenic hypertension. Lancet 1997; 349: 1330.

15 Kario K, Matsuo T, Shimada K, Pickering TG. Factors associated with the occurrence and magnitude of earthquake-induced increases in blood pressure. Am J Med 2001; 111: 379-384.

16 Parati G, Antonicelli R, Guazzarotti F, Paciaroni E, Mancia G. Cardiovascular effects of an earthquake: direct evidence by ambulatory blood pressure monitoring. Hypertension 2001; 38: 1093-1095.

17 Kamoi K, Tanaka M, Ikarashi T, Miyakoshi M. Effect of the 2004 Mid-Niigata Prefecture earthquake on home blood pressure measurement in the morning in type 2 diabetic patients. Clin Exp Hypertens 2006; 28: 719-729.

18 Azuma T, Seki N, Tanabe N, Saito R, Honda A, Ogawa Y, Suzuki H. Prolonged effects of participation in disaster relief operations after the Mid-Niigata earthquake on increased cardiovascular risk among local governmental staff. J Hypertens 2010; 28: 695-702.

19 Chen Y, Li J, Xian H, Liu S, Liu G, Lin J, Han J, Zeng Z. Acute cardiovascular effects of the Wenchuan earthquake: ambulatory blood pressure monitoring of hypertensive patients. Hypertens Res 2009; 32: 797-800

20 Petrazzi L, Striuli R, Polidoro L, Properzi G, Casale R, Pasqualetti P, Desideri G, Ferri C, Parati G. Changes in 24-hour ambulatory blood pressure monitoring during the 2009 earthquake at L'Aquila. Am J Med 2010; 123: e1-e3. 
21 Satoh M, Kikuya M, Ohkubo T, Imai Y. Acute and subacute effects of the great East Japan earthquake on home blood pressure values. Hypertension 2011; 58: e193-e194.

22 Tanaka K, Nakayama M, Tani Y, Watanabe K, Asai J, Hayashi Y, Asahi K, Watanabe T. The great East Japan earthquake: blood pressure control in patients with chronic kidney disease. Am J Hypertens 2012; 25: 951-954.

23 Watanabe K, Tani Y, Tanaka K, Hayashi Y, Asahi K, Nakayama M, Watanabe T. Acute changes in home blood pressure after the Great East Japan Earthquake among patients with chronic kidney disease in Fukushima City. Clin Exp Nephrol (e-pub ahead of print 6 December 2012; doi:10.1007/S10157-012-0750-Z).

24 Kario K, Ohashi T. Increased coronary heart disease mortality after the Hanshin-Awaji earthquake among the older community on Awaji Island. Tsuna Medical Association. J Am Geriatr Soc 1997; 45: 610-613.

25 Kario K, Ohashi T. After a major earthquake, stroke death occurs more frequently than coronary heart disease death in very old subjects. J Am Geriatr Soc 1998; 46 537-538.

26 Ix JH, Shlipak MG, Liu HH, Schiller NB, Whooley MA. Association between renal insufficiency and inducible ischemia in patients with coronary artery disease: the heart and soul study. J Am Soc Nephrol 2003; 14: 3233-3238.

27 Kaysen GA, Eiserich JP. The role of oxidative stress-altered lipoprotein structure and function and microinflammation on cardiovascular risk in patients with minor renal dysfunction. J Am Soc Nephrol 2004; 15: 538-548.

28 Chen J, Muntner P, Hamm LL, Jones DW, Batuman V, Fonseca V, Whelton PK, He J. The metabolic syndrome and chronic kidney disease in US adults. Ann Intern Med 2004; 140: 167-174.

29 Sarnak MJ, Levey AS, Schoolwerth AC, Coresh J, Culleton B, Hamm LL, McCullough PA, Kasiske BL, Kelepouris E, Klag MJ, Parfrey P, Pfeffer M, Raij L, Spinosa DJ, Wilson PW.
Kidney disease as a risk factor for development of cardiovascular disease: a statement from the American Heart Association Councils on Kidney in Cardiovascular Disease, High Blood Pressure Research, Clinical Cardiology, and Epidemiology and Prevention. Circulation 2003; 108: 2154-2169.

30 Culleton BF, Larson MG, Wilson PW, Evans JC, Parfrey PS, Levy D. Cardiovascular disease and mortality in a community-based cohort with mild renal insufficiency. Kidney Int 1999; 56: 2214-2219.

31 Foley RN, Parfrey PS, Sarnak MJ. Epidemiology of cardiovascular disease in chronic renal disease. J Am Soc Nephrol 1998; 9 (12 Suppl), S16-S23.

32 Go AS, Chertow GM, Fan D, McCulloch CE, Hsu CY. Chronic kidney disease and the risks of death, cardiovascular events, and hospitalization. N Engl J Med 2004; 351: 1296-1305.

33 Roberts MA, Hare DL, Ratnaike S, lerino FL. Cardiovascular biomarkers in CKD: pathophysiology and implications for clinical management of cardiac disease. Am J Kidney Dis 2006; 48: 341-360.

34 James GD, Schlussel YR, Pickering TG. The association between daily blood pressure and catecholamine variability in normotensive working women. Psychosom Med 1993, 55: 55-60.

35 Pickering TG, Devereux RB, James GD, Gerin W, Landsbergis P, Schnall PL, Schwartz JE. Environmental influences on blood pressure and the role of job strain. J Hypertens Supp/ 1996; 14: S179-S185.

36 Schnall PL, Schwartz JE, Landsbergis PA, Warren K, Pickering TG. A longitudinal study of job strain and ambulatory blood pressure: results from a three-year follow-up. Psychosom Med 1998; 60: 697-706.

37 Pickering T. Cardiovascular pathways: socioeconomic status and stress effects on hypertension and cardiovascular function. Ann N Y Acad Sci 1999; 896: 262-277.

Supplementary Information accompanies the paper on Hypertension Research website (http://www.nature.com/hr) 